\title{
TraNSIT: Application to Australian agriculture
}

\author{
$\underline{\text { S.L. McFallan }}^{\text {a }}$, A.J. Higgins ${ }^{\text {a }}$ A. McKeown ${ }^{\text {a }}$, C. Bruce ${ }^{\text {a }}$, O. Marinoni a and C. Chilcott ${ }^{\text {a }}$ \\ ${ }^{a}$ CSIRO Land and Water \\ Email: stephen.mcfallan@,csiro.au
}

\begin{abstract}
In Australia over 80 million tonnes of agricultural (including horticultural) output is moved between farms, storage, processors and to markets each year. These movements are characterised by long supply chains; distances between production, processing and markets are often thousands of kilometres, and rarely less than hundreds. To compete, farmers and producers require efficient transport options, which in turn, relies on uninterrupted transport infrastructure and an optimal mix of rail and heavy vehicles enabled by considered policy.
\end{abstract}

To provide a holistic view of transport logistics costs and benefits due to infrastructure investments and policy changes in agriculture supply chains in Australia, CSIRO developed the Transport Network Strategic Investment Tool (TraNSIT). TraNSIT was identified as the preferred tool to help in unlocking a more efficient agricultural transport system to meet the Australian Government's key objective of the Agricultural Competitiveness White Paper of building the infrastructure of the 21 st century. Under this programme of work, TraNSIT was able to provide governments, industry, the farming community and other stakeholders with a baseline of freight transport costs between Australian agricultural value chain enterprises, along with a capacity to identify and evaluate a range of scenarios to minimise transport costs and maximise long-term profitability.

The extension of TraNSIT to broader Australian agricultural commodities was conducted with support, input and validation from over 80 organisations, agencies and associations representing the agricultural/horticultural and transport sectors. Aside from the insights used to ensure the model reflected industry logistic systems and processes, these contributors provided data for 222,000 enterprises across the commodities supply chains including farms, processors, storage facilities, saleyards, abattoirs, export depots, supermarkets and distribution centres which were incorporated into TraNSIT. The enterprises represented supply chain distribution points for the commodities modelled which were livestock, diary, grains, cotton, rice, sugar, stockfeed and horticulture. From this data a set of synthetic trips were created so that annual/monthly total tonnage (or head) transported across the road/rail network were representative of past movements. In total there were 332,000 different origin to destination paths created. This paper highlights the application of TraNSIT to $98 \%$ of Australia's Agricultural production and the importance of the industry and government support to identify synergistic efficiency gains in transport. It represents the largest logistics data set assembled and transport modelling ever conducted for Australian agriculture.

Keywords: TraNSIT, Supply chains, infrastructure investment, transport optimisation 


\section{INTRODUCTION}

Transport infrastructure is essential to moving over 80 million tonnes of Australian agricultural output between farms, storage, and processors and to markets each year. These movements are characterised by long supply chains with distance between production, processing and markets often exceeding thousands of kilometres, and rarely less than hundreds. While most key freight routes are sealed, much of the sparse rural road network, particularly near production areas, is unsealed and often in poor condition. About $80 \%$ or $657,000 \mathrm{~km}$ of the nation's roads are managed by local governments and about $11 \%$ of these roads are considered in poor condition (ALGA 2016). These poor road conditions substantially reduce average travel speeds (often to less than $40 \mathrm{~km} / \mathrm{hr}$ ), damage transported livestock and horticulture, and increase maintenance costs of heavy vehicles. Unlike other resource commodities such as minerals and fuels, the agricultural industry is characterised by a very large number of transport paths to facilities such as storage, processing and saleyards, which can substantially vary by time of year and between seasons. The industry uses a large proportion of Australia's rural road network, and has a high reliance on minor roads.

This paper captures some of the methods and outputs from a recent "Building the infrastructure of the 21st Century" under the Agricultural Competitiveness White Paper (http://agwhitepaper.agriculture.gov.au/) project. The project - TraNSIT: Unlocking options for efficient logistics infrastructure in Australian agriculture - extended TraNSIT to broader agricultural and horticultural supply chains across Australia.

\section{METHODOLOGY}

TraNSIT is a computer-based model, coded in Python and FORTRAN, and utilizes the network analyst features of ArcMap. It is a modularised tool, outlined in Figure 1, where data for each agriculture sector is an input to the core engine, along with the infrastructure or regulatory scenarios to test. The tool has an Australian road and rail network and transport models module capturing the underlying physical infrastructure and transport options, a supply chain module with detailed data on commodity movements and processes as well as a module capturing regulations and scenario parameters. The road layer shown in Figure 2 was constructed using shape files defining location, ranking, access restrictions and other road information (breakdown pads, biosecurity restrictions, rest stops) from several road agency sources. The roads were classed as primary, secondary and minor, with these roads further broken into segments with attributes containing surface type, width, speed limit and any special limits (e.g. one-way bridges). These data were collected from the transport departments of each state/territory in Australia. All of these attributes affect average speed and transport cost per kilometre. The road layer required enhancements (e.g. creating connections, correcting locations of some roads) to provide a fully routable road layer.

TraNSIT uses a ground-up costing model for both road and rail, to provide a cost per $\mathrm{km}$ or hour for each trip. The vehicle model accounts for all major variables that impact operating cost, including: vehicle type, driver cost, fuel cost, maintenance, capital cost and depreciation, tyres and registration. A snapshot of the transport costs for different speeds and vehicles is contained in Table 1. The model for rail was derived from one produced by Australian Rail Track Corporation, and parameterised for other rail corridors (e.g. Queensland Rail). It accommodates all of the above rail costs, including rolling stock capital costs and maintenance, depreciation, crew costs, train length, payload, travel time, and track access charges.

Historical data on commodity movements between enterprises (e.g. farm to processor) are used to derive statistical probabilities of transport between farms (in case of cattle movement), farm to storage, farm to processor, etc. For example, farms would more likely supply a closer processor (depending on price paid) compared to a processor with a much longer travel distance. These probabilities are calibrated so that distribution of travel distances (including interstate) are similar to those recorded in past actual data.

Once the set of movements have been produced, TraNSIT finds the optimal route (based on transport cost) and selection of vehicle types, for each Origin-Destination (O-D) pair input. Optimal road sections travelled for each O-D pair are saved. These road sections can be constrained by access restrictions such as vehicle size/load limit which will determine the route final set of route segments. Once the optimal set of segments for all O-D pairs are saved, Python scripts calculate the cost of transport and number of vehicles for a given resource flow between each O-D pair. These are then aggregated over all O-D pairs to provide a total cost of transport for the scenario. It currently takes about 16 hours (on 25 cores - Dual Xeon CPU 3.3GhZ processor) to run all of steps of TraNSIT shown in Figure 1 for the 332,000 different O-D's across all agriculture, and the combined model outputs produced about 429 gigabytes of outputs. 
Table 1. Sample of the vehicle transport costs

Additional maintenance costs Modelled cost $(\$ / \mathrm{km})$ per travel speed $(\$ / \mathrm{km})$

\begin{tabular}{lllllll} 
Vehicle type & $100 \mathrm{~km} / \mathrm{h}$ & $60 \mathrm{~km} / \mathrm{h}$ & $20 \mathrm{~km} / \mathrm{h}$ & \multicolumn{2}{l}{ Good Unsealed } & Poor Unsealed Idle cost $(\$ / \mathrm{hr})$ \\
\hline Semitrailer & 1.91 & 2.58 & 6.11 & 0.09 & 0.26 & 119 \\
B-Double & 2.35 & 3.13 & 7.36 & 0.13 & 0.39 & 141 \\
Type 1 & 2.71 & 3.54 & 6.81 & 0.16 & 0.49 & 169 \\
Type 2 & 3.43 & 4.36 & 8.22 & 0.24 & 0.72 & 177
\end{tabular}

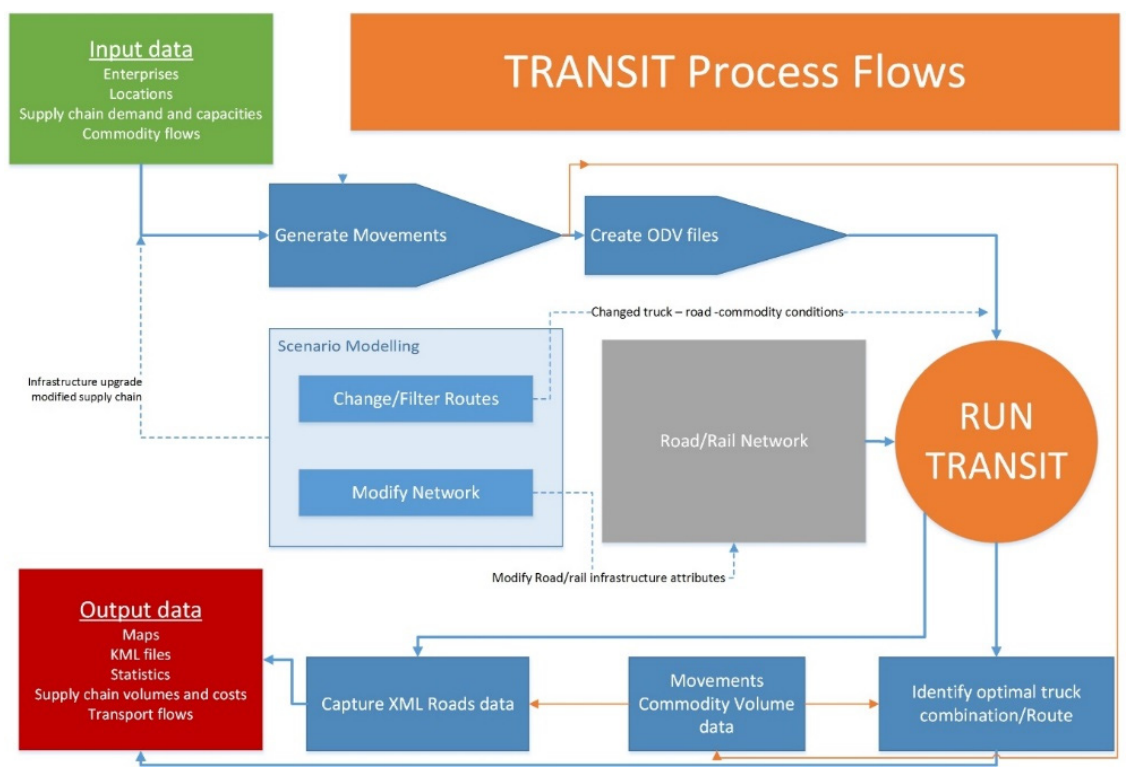

Figure 1. Process diagram of TraNSIT, comprising the stages from set up to running of each model component

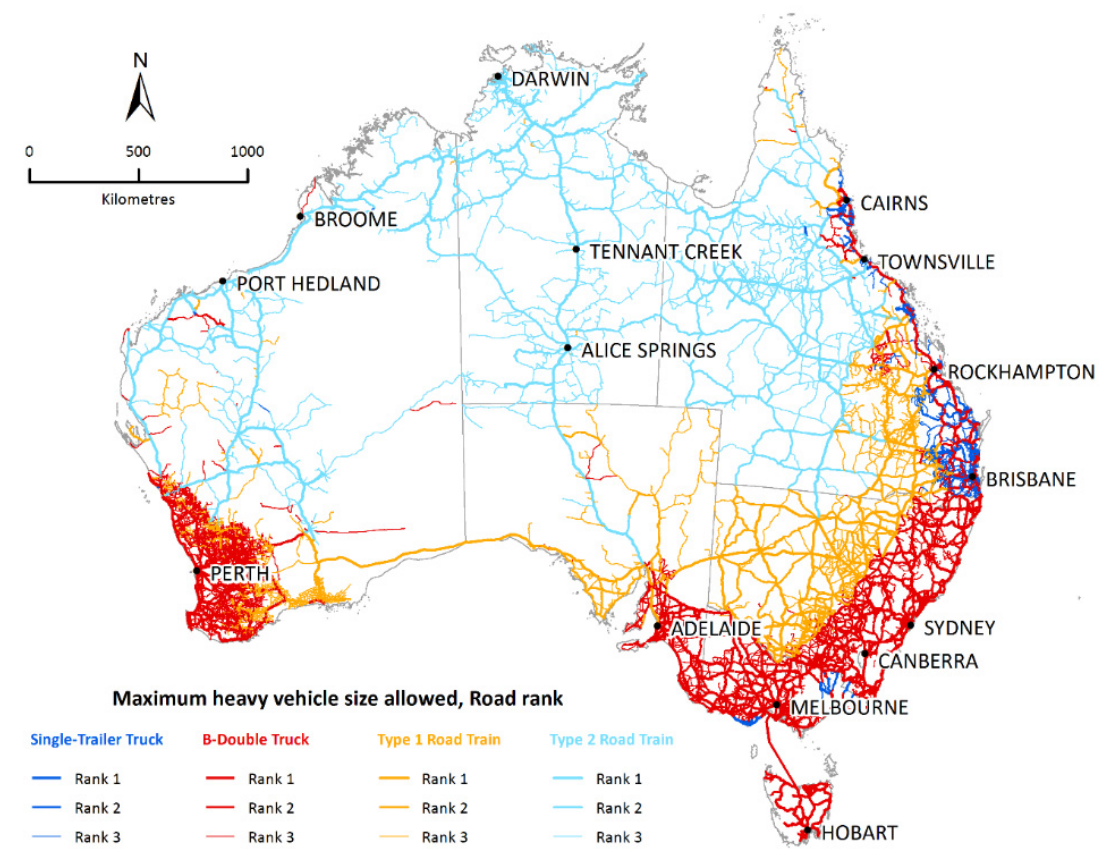

Figure 2. Current road layer used in TraNSIT showing road rankings and heavy vehicle access. 


\section{AGRICULTURAL SUPPLY CHAINS}

The extension of TraNSIT to broader Australian agricultural commodities was conducted with support, input and validation from over 80 organisations, agencies and associations representing the agricultural/horticultural and transport sectors. Commodities included in TraNSIT were: beef, sheep/goats, diary, pigs, poultry, grains (wheat, sorghum, oats, barley, chickpeas, canola, lentils, maize, peas, durum, fababeans), cotton, rice, sugar, buffalo, stockfeed, horticulture (oranges, mandarins, potatoes, broccoli, onions, apples, pears, mangoes, bananas, pumpkins, melons, carrots, lettuces and pineapples). TraNSIT incorporated data for 222,000 enterprises including: 216,000 farms or production locations; 350 processors; 500 saleyards/feedlots; 530 storage facilities; and 3600 supermarkets and distribution centres. The data representing agricultural enterprises and supply chain paths were used to create a set of monthly vehicle and rail movements for an average year in TraNSIT.

De-identified GIS farm paddock layers or farm locations were used to produce representative production locations for low and high production years where available from industry organisations. Where these farm layers were not available, a high resolution national land use map, produced by the Australian Bureau of Agricultural and Resource Economics and Sciences (ABARES) was used to identify the locations of each crop (commodity) class. Information on average annual yields for each crop at each production location and regional harvest time windows were used to estimate monthly freight volumes from the farm.

The Australian Beef industry data was incorporated prior to this project (Higgins et al 2016) and used detailed industry provided data. Transport volumes between enterprises were based on 2009 to 2013 with live export based 2014/2015 figures. The beef supply chains were updated in this project to include the transport of grains from storage to feedlots (Figure 3). The grains industry were also very supportive and provided significant input in terms of processes, supply chains, annual throughputs and yields. The supply chain paths and transport tonnages for grains were mapped in accordance with Figure 4 using historical (2015/2016) throughputs for each grain storage facility, port export data, and demand from feedlots, stock feed manufacturers and flour mills. For the purposes of this project, the scope of the supply chains ends at the flour mill due to the complex secondary processing and chain paths to domestic markets, where limited data is available. Demands from feedlots and stockfeed manufacturers (for intensive livestock systems) were a function of number of animals at each feedlot and livestock system (e.g. poultry farm, piggery, dairy) and feed requirements. Grain can be transported from the storage facilities to ports and flour mills, either by road or rail. The initial supply chain paths and grain volumes produced by TraNSIT were validated and refined with the major grain traders, particularly for rail usage and volumes at different locations.

A set of synthetic trips representing the supply chains were created so that the annual/monthly total tonnage (or head) transported across the road/rail network were representative of past movements. In total there were 332,000 different origin to destination paths created representing 635,000 shipments totaling 5,250,000 trailer loads and 755,000 rail wagons. TraNSIT accommodates interdependencies between the livestock and cropping supply chains, with nearly 12 million tonnes of grain (Feed and Grain S\&D Report 2014) being used in feedlots and intensive livestock systems. Further details on the complete supply chain for each commodity is available in the report (Higgins el al 2017).

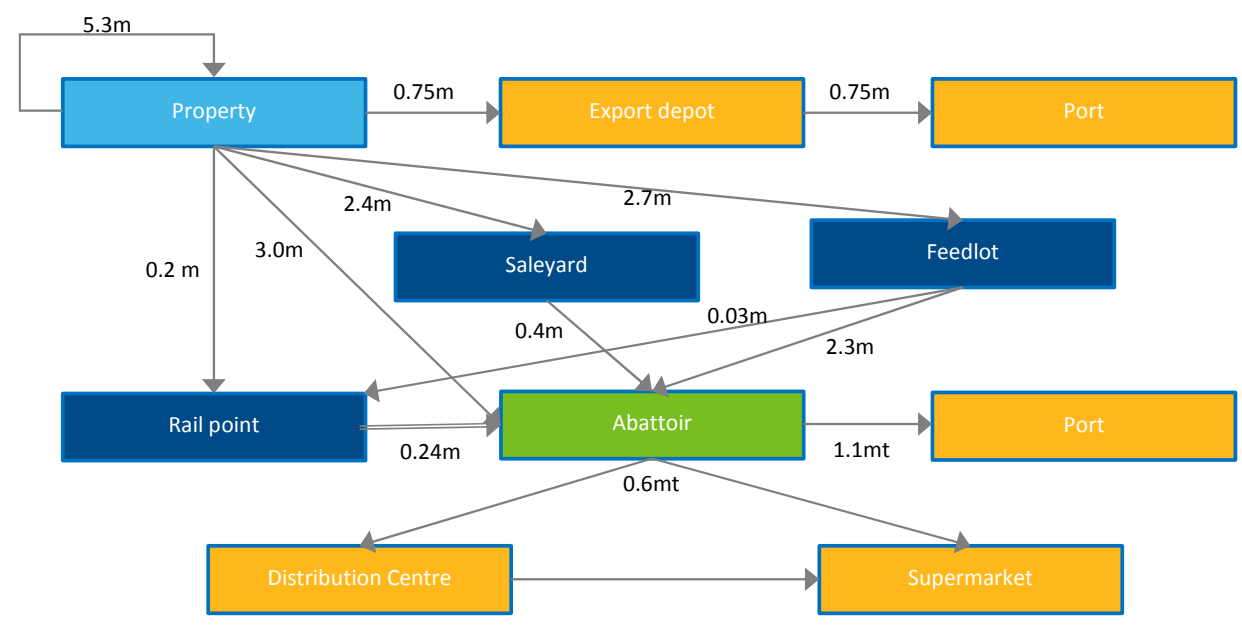

Figure 3. Modelled supply chain paths and annual transport volumes for beef. $\mathrm{m}=$ million head; $\mathrm{mt}=$ million tonnes 


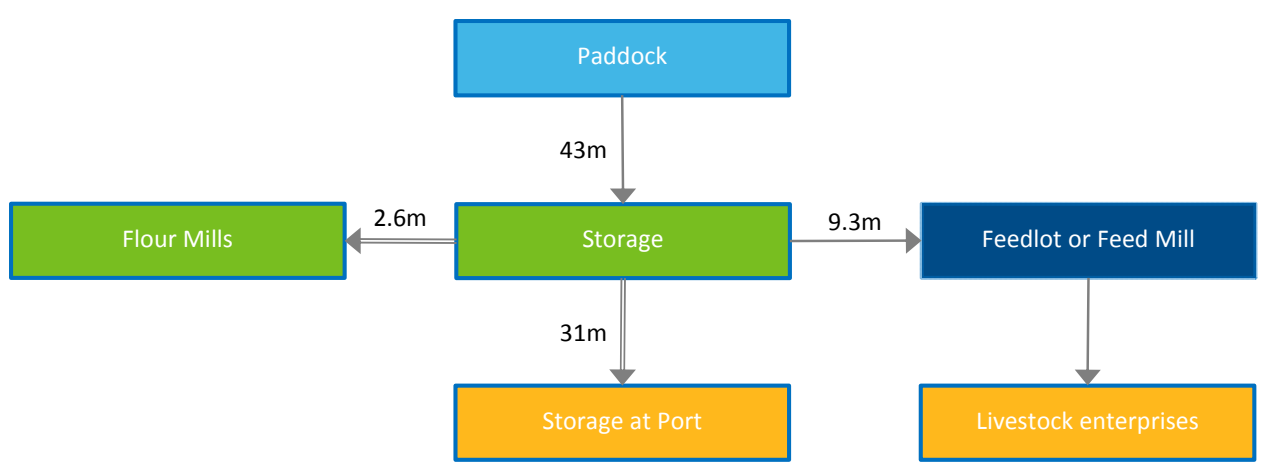

Figure 4. Modelled supply chain paths for grains including transport tonnages

\section{OUTPUTS}

The primary outputs from TraNSIT contain the number of vehicles (of each type) and related transport costs for every road/rail segment across Australia. These can be aggregated to provide total costs and freight flows for the baseline and any scenario. For this project, this information will be made available to industry and government agencies in the form of a GIS shape or KMZ file (for Google Earth), subject to any necessary desensitising of data. These outputs will not reveal information at enterprise level. These supply chain maps can be disaggregated further to region, to help identify bottlenecks and hot spots. Outputs can also be disaggregated by road segment to show vehicle numbers by commodity or vehicle type including direction. A baseline analysis provides information on the number of vehicles travelling along each road/rail segment, and needs to be undertaken before case studies can be tested. The main outputs from the baseline are:

- number of vehicles or trains using each transport network segment by commodity, month of year, origin and destinations routes.

- detailed cost of road and rail transport for every vehicle and rail trip.

The baseline freight density map for all commodities is shown in Figure 5 for road movements.

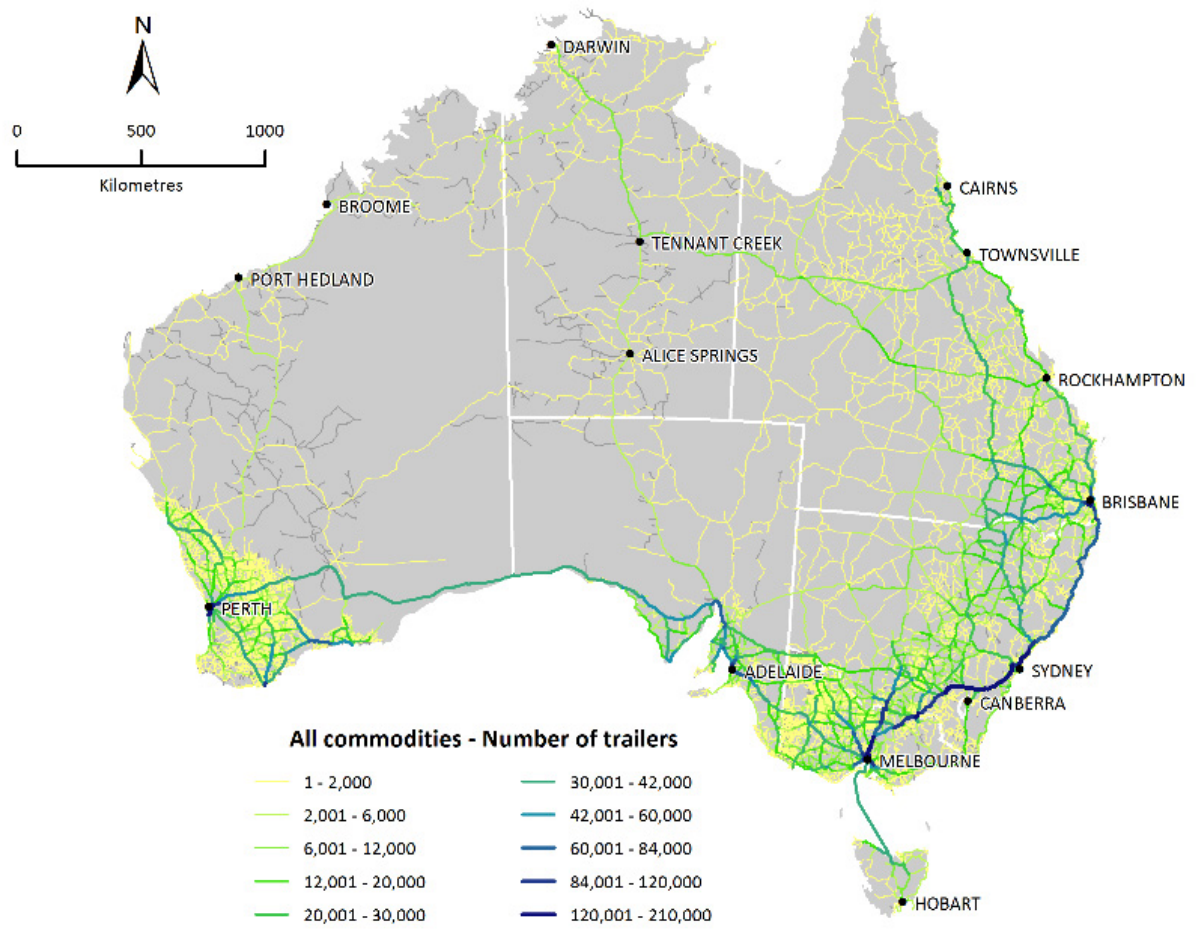

Figure 5. Baseline annual trailer (semi-trailer equivalent) freight flow map for all modelled commodities. 
The baseline is a representation of the actual freight movements across the road (and rail) network, based on the representative years for each agricultural commodity. Freight density maps can be disaggregated for individual commodities. Unused road segments are left as dark grey.

A summary of modelled annual transport cost for each commodity is shown in Table 2. These summary transport costs can be disaggregated by state, local government area, individual roads, etc. The total annual transport cost (road and rail) is $\$ 5.8$ billion or $9.8 \%$ of the total farm gross value of production in 2015/2016 (ABARES 2017). This percentage would be slightly higher if the current version of TraNSIT included the remainder of Australian agriculture transport. It currently has about $98 \%$ of agriculture volume on road and rail (excluding cane rail). The total greenhouse gas emissions are $6.6 \%$ of the baseline 2010 emissions for noncar road vehicles in Australia (BITRE 2007). Grains account for nearly $90 \%$ of all rail costs. The rail costs are sensitive to parameters used in the rail costing model embedded in TraNSIT, particularly the wagon capacity, axel load limits, travel time, capital costs and the number of round trips the rolling stock is used per year.

Table 2. Total cost of transport (annual average) for each commodity. These represent the total transport costs across the supply chain from paddock to domestic market (except grain) or port.

\begin{tabular}{|c|c|c|c|}
\hline & Road & Rail & Road CO2 (tonnes) \\
\hline Beef\# & $\$ 572,438,780$ & $\$ 31,656,477$ & 244,082 \\
\hline Grain & $\$ 2,149,790,452$ & $\$ 487,280,313$ & 862,184 \\
\hline Pigs & $\$ 29,012,052$ & & 11,156 \\
\hline Rice & $\$ 134,177,281$ & & 55,437 \\
\hline Dairy & $\$ 881,736,430$ & & 337,294 \\
\hline Sugar & $\$ 52,245,332$ & $\$ 9,951,700$ & 16,174 \\
\hline Sheep/Goats & $\$ 221,773,671$ & & 85,883 \\
\hline Cotton & $\$ 76,914,483$ & $\$ 13,259,573$ & 36,385 \\
\hline Horticulture & $\$ 617,806,580$ & & 256,295 \\
\hline Post Processing* & $\$ 249,680,948$ & & 98,080 \\
\hline Mixed (DC to Market) ${ }^{\wedge}$ & $\$ 284,535,545$ & & 109,157 \\
\hline Poultry & $\$ 28,196,377$ & & 8,766 \\
\hline Total & $\$ 5,298,307,931$ & $\$ 542,148,063$ & $2,120,893$ \\
\hline
\end{tabular}

\#including a small number (20,000 head) of Buffalo; *includes boxed beef, chicken, lamb, pork to domestic markets and port; ^mixture of horticulture and post processed commodities between DC's and supermarkets

\section{DISCUSSION AND CONCLUSIONS}

TraNSIT uses the largest and most rigorous supply chain dataset ever assembled across Australian agriculture, and a large proportion of the industry data was provided, much of which was provided under confidentiality agreements. Due to the sensitive nature of the industry data provided and used in TraNSIT, the model cannot be used in applications that allow an organisation to gain competitive commercial advantage. A proposed future version of TraNSIT will remove this sensitivity and allow an organisation to input its own data or forecasts and use the model to optimise its own logistics.

TraNSIT is readily extendable to other commodities and road users by incorporating information representing the locations of enterprises and their new supply chains. This includes volumes of commodity moved between enterprises (origins and destinations) and transport characteristics (e.g. vehicle types, vehicle access) relating to these commodities. TraNSIT can examine transported related cost savings for a wide range of infrastructure investment and regulatory opportunities, including:

- Analysing the impact of road upgrades, e.g. sealing, widening, first/last mile improvements, upgrading roads for higher productivity vehicles and bridges. This has previously been undertaken for the northern Australian beef industry (report accessible from www.csiro.au/transit);

- Informing improvements to rail infrastructure at different locations including new freights hubs and integration with road transport; 
- Informing optimisation of supply chains in the private sector, such as location of new facilities (e.g. Garcia-Flores et al (2014));

- Forecasting freight volumes, supply chain dynamics and bottlenecks under future production scenarios, from farm to national scale;

- Testing potential outcomes for changes in policy, e.g. driver fatigue, use of high productivity vehicles, road pricing;

- Comparing infrastructure investment and regulatory-change opportunities that maximise transport cost reductions for a given (limited) investment budget.

Detailed examples of infrastructure and regulatory analysis can be seen in McFallan et al (2015).

This project delivered the agriculture sector and related stakeholders with information on existing transport costs across the supply chain and can provide details of savings on options to reduce transport costs through identified road and rail inefficiencies such as bottlenecks and pinch points.

\section{REFERENCES}

ABARES (2017). Agricultural commodities. Research by the Australian Bureau of Resource Economics and Sciences. March Quarter 2017. Data.daff.gov.au.

ALGA (2016). Local Infrastructure Driving Productivity. Australian Local Government Association Congress Bulletin.

http://alga.asn.au/site/misc/alga/downloads/publications/ALGA_Roads16_CongressBulletin.pdf?Menu=5 0,600

BITRE (2007). Greenhouse gas emissions from Australian transport: projections to 2020. Working paper 73, bitre.gov.au/publications.

Feed Grain S\&D Report (2014). Australian Feed Supply and Demand Report 2013/2014. Prepared by JCS Solutions.

Garcia-Flores R, Higgins A, Prestwidge D, McFallan S (2014). Optimal location of spelling yards for the northern Australian beef supply chain. Computers and Electronics in Agriculture. 2014, 102,134-145. https://doi.org/10.1016/j.compag.2014.01.015).

Higgins A, McFallan S, Bruce C, Laredo L, McKeown A, Beaty M, Marinoni O. (2016). Informing major government programs for rural transport infrastructure in Australia using TraNSIT. Transportation Research A, Under review.

Higgins AJ, McFallan S, McKeown A, Bruce C, Marinoni O, Chilcott C, Stone P, Laredo L, Beaty M. (2017) TraNSIT: Unlocking options for efficient logistics infrastructure in Australian agriculture. CSIRO, Australia.

McFallan SL, Higgins AJ, Laredo L, Prestwidge D. (2015) TraNSIT: identifying optimal infrastructure investment; 21st International Congress on Modelling and Simulation, Gold Coast, Australia, 29 Nov to 4 Dec 2015 www.mssanz.org.au/modsim2015 